\title{
Mechanisms of Gallstone Formation in Women \\ Effects of Exogenous Estrogen (Premarin) and Dietary Cholesterol on Hepatic Lipid Metabolism
}

Gregory T. Everson, Carol McKinley, and Fred Kem, Jr.

Division of Gastroenterology and Hepatobiliary Research Center, University of Colorado School of Medicine, Denver, Colorado 80262

\begin{abstract}
Our aim was to define mechanisms whereby conjugated estrogens (Premarin, exogenous estrogen; Ayerst Laboratories, New York) increase the risk of developing cholesterol gallstones and to determine the role, if any, of dietary cholesterol. We studied gallbladder motor function, biliary lipid composition and secretion, cholesterol absorption, cholesterol synthesis and esterification by peripheral blood mononuclear cells, the clearance of chylomicron remnants, and bile acid kinetics in 29 anovulatory women. 13 were studied on both a low $(443 \pm 119$ $\mu \mathrm{mol} / \mathrm{d})$ and high $(2,021 \pm 262 \mu \mathrm{mol} / \mathrm{d})$ cholesterol diet. Premarin increased the lithogenic index of bile $(P<0.05)$, increased biliary cholesterol secretion $(P<0.005)$, lowered chenodeoxycholate $(C D C A)$ pool $(P<0.001)$ and synthesis $(P$ $<0.05)$, altered biliary bile acid composition ([CA + DCA]/ CDCA $\uparrow, P<0.005)$, stimulated cholesterol esterification $(P$ $<0.03$ ), and enhanced the clearance of chylomicron remnants $(P=0.07)$. Increases in dietary cholesterol stimulated the biliary secretion of cholesterol $(P=0.07)$, bile acid $(P<0.05)$, phospholipid $(P=0.07)$, and as a result, did not alter lithogenic index. The reduction in CDCA pool and synthesis by Premarin was reversed by increasing dietary cholesterol. Off Premarin, only $24 \%$ of the increase in cholesterol entering the body in the diet was recovered as biliary cholesterol or newly synthesized bile acid. On Premarin, 68\% of this increase in cholesterol was recovered as these biliary lipids. We conclude that Premarin increases biliary cholesterol by enhancing hepatic lipoprotein uptake and inhibiting bile acid synthesis. These actions of Premarin divert dietary cholesterol into bile. (J. Clin. Invest. 1991. 87:237-246.) Key words: bile acid kinetics • cholesterol gallstones • chylomicron remnant clearance • conjugated estrogens • gallbladder function $\bullet$ retinyl palmitate
\end{abstract}

\section{Introduction}

The risk of developing cholesterol gallstones is increased by pregnancy $(1-5)$, contraceptive steroids $(6,7)$, and conjugated estrogens $(8,9)$. Although the mechanisms whereby female steroid hormones induce gallstones are incompletely defined, previous studies have shown that female steroid hormones significantly alter hepatobiliary physiology. For example, gallbladder volume increases during late pregnancy (10-12), and the

Address reprint requests to Dr. Everson, Division of Gastroenterology, University of Colorado School of Medicine, 4200 East 9th Avenue, B-158, Denver, CO 80262.

Received for publication 31 July 1989 and in revised form 13 July 1990

J. Clin. Invest.

(C) The American Society for Clinical Investigation, Inc. $0021-9738 / 91 / 01 / 0237 / 10 \quad \$ 2.00$

Volume 87, January 1991, 237-246 emptying of the gallbladder is slowed by pregnancy, use of contraceptive steroids, $(10,13)$, or progestin (14). The cholesterol content of bile is increased in late pregnancy (15) and during use of contraceptive steroid mixtures $(13,16,17)$, ethinyl estradiol $(18,19)$, or a combination of conjugated estrogens and medroxyprogesterone (20). In addition, bile acid metabolism is altered by pregnancy $(15)$ and contraceptive steroids $(13,17$, $21)$. Despite these observations, there have been no comprehensive studies of the effects of estrogen, administered alone, on hepatobiliary function.

Studies of the effects of dietary cholesterol on biliary lipid metabolism in humans have given conflicting results. DenBesten et al. (22) and Lee et al. (23) found that increases in dietary cholesterol were associated with increases in the cholesterol saturation of bile. However, Dam et al. (24) and Anderson and Hellstrom (25) observed no increase in biliary cholesterol with increases in dietary cholesterol. These discrepant results have been attributed to differences in the populations studied and diets used. Increases in dietary cholesterol have been associated with increased absorption of absolute amounts of cholesterol, reduced synthesis of cholesterol, and increased excretion of cholesterol through the biliary tract (26-28). There have been no comprehensive studies in healthy people of the effects of dietary cholesterol on hepatic lipid metabolism.

We evaluated the effects of Premarin (exogenous estrogen, Ayerst Laboratories, New York), a commonly prescribed preparation of conjugated estrogens, on hepatobiliary function during different dietary intakes of cholesterol. We determined whether Premarin or dietary cholesterol altered gallbladder motor function, the lipid composition of gallbladder bile, the secretion of biliary lipids, cholesterol synthesis and esterification by peripheral blood mononuclear cells, the absorption of cholesterol from the intestine, the plasma clearance of chylomicron remnants labeled with retinyl palmitate, and the steady-state kinetics of bile acids.

\section{Methods}

\section{Materials}

The following materials and equipment were used in these studies: $\left[4-{ }^{14} \mathrm{C}\right]$ cholesterol, $\left[1,2-{ }^{3} \mathrm{H}\right]$ cholesterol, $\left[2-{ }^{14} \mathrm{C}\right]$ acetate, and $\left[2-{ }^{14} \mathrm{C}\right]-$ mevalonolactone (New England Nuclear, Boston, MA); Budgetsolve (Research Products International Corp., Mount Prospect, IL); Lymphoprep (Nygaard and Company, Oslo, Norway); sincalide (CCK8) ${ }^{1}$ (E. R. Squibb \& Sons, Inc., Princeton, NJ); retinyl palmitate (Roche Chemical Co., Nutley, NJ); SepPak C18 cartridges (Waters Associates, Milford, MA); C8-liquid chromatographic cartridges (J. T. Baker

1. Abbreviations used in this paper: ACAT, acyl coenzyme A-cholesterol-acyltransferase; CA, cholic acid (cholate); CCK8, sincalide; CDCA, chenodeoxycholate; DCA, deoxycholate; FV, fasting volume; HMG, 3-hydroxy-3-methylglutaryl (coenzyme A reductase); RV, residual volume. 
Chemical Co., Phillipsburg, NJ, and Analytichem International, Harbor City, $\left.\mathrm{CA}^{2}\right) ;\left[24-{ }^{13} \mathrm{C}\right]$ cholate, $\left[24-{ }^{13} \mathrm{C}\right]$ chenodeoxycholate, $[11,12$ $\left.{ }^{2} \mathrm{H}\right]$ chenodeoxycholate, $\left[2,2,4,4-{ }^{2} \mathrm{H}\right]$ cholate (Merck Isotopes, Montreal, Canada); model 5790/5970B gas chromatography/mass spectroscopy (GC/MS) system (Hewlett Packard Co., Englewood, CO); model M45 Waters high-performance liquid chromatograph with 710B WISP automatic injector.

\section{Subjects}

This study was approved by the Human Subject Committee of the University of Colorado School of Medicine. All subjects (Table I) were paid volunteers and gave written, informed consent. 29 healthy, anovulatory women (aged 28-62 yr) were each studied on or off Premarin for at least 4 wk. $^{3} 16$ were studied on a diet containing moderate amounts of cholesterol $(1,316 \pm 262 \mu \mathrm{mol} / \mathrm{d}$; two studies per subject). 13 subjects were studied on both a low $(443 \pm 119 \mu \mathrm{mol} / \mathrm{d})$ and high $(2,021 \pm 262$ $\mu \mathrm{mol} / \mathrm{d}$ ) cholesterol diet (four studies per subject). 25 took $1.25 \mathrm{mg} / \mathrm{d}$ and four took $0.625 \mathrm{mg} / \mathrm{d}$ of Premarin as prescribed by their personal physicians.

\section{Study protocol}

The order of Premarin treatment was random, but in the protocol examining the effects of dietary cholesterol, subjects were first studied on the low cholesterol diet. Subjects were on a given diet for at least 4 wk and studied during the last week of each study period. The following were determined at each study period: plasma lipids and routine chemistries, gallbladder motor function, cholesterol absorption, cholesterol synthesis and esterification, bile acid kinetics, plasma clearance of retinyl palmitate, and rates of biliary lipid secretion.

\section{Diet}

The Clinical Research Center dietician instructed the subjects in diets containing the various amounts of cholesterol and in the proper maintenance of a daily food diary. The diet and the diary were periodically reviewed by the dietician who calculated the daily cholesterol intake from diet records that were kept throughout the study period (29).

\section{Procedures}

Gallbladder motor function. The volume and contraction of the gallbladder were determined by realtime ultrasonography (30). Fasting volume (FV) was defined as volume after an overnight fast. Residual volume (RV) was defined as the minimum volume achieved during the $2 \mathrm{~h}$ after ingestion of a meal (11) or infusion of CCK8 $(0.02 \mu \mathrm{g} / \mathrm{kg}$ per h). The percent of fasting volume ejected $(\% \mathrm{E})$ and rate constant of emptying $(k)$ were calculated as described (30).

Cholesterol absorption and synthesis. This parameter was measured by the dual-isotope ratio method and cholesterol synthesis was determined in peripheral blood mononuclear cells as previously described (16). The variation between duplicate measurements of cholesterol absorption was $3.8 \pm 2.7 \%$ and between duplicate measurements of cholesterol synthesis $5.7 \pm 5.8 \%$.

Cholesterol esterification. Cholesterol esterification by peripheral blood mononuclear cells was measured by incubation with $\left[2-{ }^{14} \mathrm{C}\right]-$

2. The packing material of the $\mathrm{C} 8$ liquid chromatographic cartridges that were initially used was altered by the manufacturer without notice (J. T. Baker Chemical Co.). The altered C8-bonded phase exhibited completely different chromatographic properties in the extraction and elution of bile acid methyl esters. As a result, bile acids were not quantitatively recovered during this preparative step in some studies. The poor recoveries contributed to the inability to complete all kinetic analyses. Another C8 cartridge (Analytichem International, Inc.) has demonstrated consistent recoveries for bile acid methyl esters and is currently being used in our laboratory for these assays.

3. Premarin is a mixture of the sulfate esters of estrone (60\%), equilin (25\%), $17 \alpha$-dihydroequilin (5-10\%), 17 -estradiol, equilenin, and $17 \alpha$ dihydroequilenin; see Johnson et al. (67).
Table I. Characteristics of Study Subjects and Number of Studies Completed off and on Premarin under Each Dietary Condition

\begin{tabular}{|c|c|c|c|c|c|c|}
\hline Characteristics of subjects & \multicolumn{2}{|c|}{$\overline{\mathbf{X}}+\mathrm{SD}$} & \multicolumn{4}{|c|}{ Range } \\
\hline Age $(y r)$ & \multicolumn{2}{|c|}{$43 \pm 13$} & \multicolumn{4}{|c|}{$28-62$} \\
\hline Weight $(k g)$ & \multicolumn{2}{|c|}{$69 \pm 16$} & \multicolumn{4}{|c|}{$47-112$} \\
\hline Percent ideal weight & \multicolumn{2}{|c|}{$124 \pm 24$} & \multicolumn{4}{|c|}{$84-190$} \\
\hline Body surface area $\left(\mathrm{m}^{2}\right)$ & \multicolumn{2}{|c|}{$1.74 \pm .20$} & \multicolumn{4}{|c|}{$1.49-2.23$} \\
\hline \multirow[t]{2}{*}{ Dose of Premarin $(m g / d)$} & \multicolumn{2}{|c|}{ NA } & \multicolumn{4}{|c|}{$0.625(n=4), 1.25(n=25)$} \\
\hline & \multicolumn{2}{|c|}{$\begin{array}{l}\text { Low CH } \\
(n=13)\end{array}$} & \multicolumn{2}{|c|}{$\begin{array}{l}\text { Medium } \\
\text { CH } \\
(n=17)\end{array}$} & \multicolumn{2}{|c|}{$\begin{array}{l}\text { High CH } \\
(n=13)\end{array}$} \\
\hline Studies completed* & Off & On & Off & On & Off & On \\
\hline Gallbladder function & 3 & 3 & 6 & 6 & 4 & 4 \\
\hline \multicolumn{7}{|l|}{ Gallbladder lipid } \\
\hline composition & 12 & 11 & 6 & 6 & 12 & 11 \\
\hline Biliary lipid secretion & 11 & 12 & 6 & 5 & 11 & 10 \\
\hline Cholesterol absorption & 12 & 13 & 10 & 9 & 12 & 13 \\
\hline Cholesterol synthesis & 12 & 12 & 10 & 10 & 11 & 12 \\
\hline Cholesterol esterification & 6 & 6 & 10 & 9 & 6 & 5 \\
\hline \multicolumn{7}{|l|}{ Chylomicron remnant } \\
\hline clearance & 11 & 11 & 0 & 0 & 10 & 13 \\
\hline Bile acid kinetics & 11 & 12 & 16 & 16 & 11 & 11 \\
\hline
\end{tabular}

Abbreviations: $\overline{\mathrm{X}} \pm \mathrm{SD}$, mean \pm standard deviation; $\mathrm{CH}$, dietary cholesterol; NA, not applicable.

* "Off" refers to studies during the control period, off Premarin.

"On" refers to studies during the treatment period, on Premarin.

mevalonolactone $(1 \mu \mathrm{mol})$ for $5 \mathrm{~h}$ at $37^{\circ} \mathrm{C}$ in $95 \% \mathrm{O}_{2}, 5 \% \mathrm{CO}_{2}$ in $1 \mathrm{ml}$ RPMI 1640, 25 mM Hepes buffer, pH 7.4, supplemented with penicillin and streptomycin (31). Cholesterol esters were extracted with $\mathrm{CHCl}_{3} / \mathrm{MeOH}(2: 1)$ and isolated using a silica-based liquid chromatographic cartridge and radioactivity was assayed. Synthesis was expressed as picomoles of mevalonate converted to cholesterol ester per hour per $10^{7}$ mononuclear cells. The variation in duplicate measurements was $16.0 \pm 19.7 \%$.

Biliary lipid composition of gallbladder bile and biliary lipid secretion. Most of the procedures and analytical techniques have been previously described in detail (15). A nasoduodenal tube was placed, and gallbladder contraction was stimulated by an intravenous infusion of CCK8 $(0.02 \mu \mathrm{g} / \mathrm{kg}$ per min) followed by intraduodenal infusion of liquid formula $(6 \mathrm{~h})$ containing the nonabsorbable marker, $\left[{ }^{14} \mathrm{C}\right] \mathrm{PEG}$ 4000. Gallbladder bile composition was measured in CCK8-stimulated duodenal bile using standard techniques $(16,32,33)$ and lipid secretion rates calculated from marker dilution (34). Secretion rates were determined from samples obtained at 30-min intervals after initiation of formula infusion ( 12 samples per $6 \mathrm{~h}$ ). The coefficients of variation in mean secretion rate were $23 \%, 24 \%$, and $22 \%$ for bile acid, phospholipid, and cholesterol.

Hepatic clearance of chylomicron remnants. The rationale and methods have been described in detail (35-41). Retinyl palmitate was given by mouth, and blood was drawn periodically for $24 \mathrm{~h}$ (16). Plasma concentrations of retinyl palmitate were measured by HPLC and clearance used as an estimate of the hepatic clearance of chylomicron remnants. Clearance was calculated from the area underneath the plasma concentration curve and was corrected for the mean percent absorption of the administered retinol (96.4\%) and for percentage esterified with palmitic acid (71\%) (39).

Bile acid kinetics. A method utilizing stable isotopes and serum sampling was used (42). Bile acids labeled with stable isotopes $\left({ }^{13} \mathrm{C}\right.$ or ${ }^{2} \mathrm{H}$ ) were given orally, and blood samples were obtained daily for the 
subsequent 4-5 d. Bile acids were extracted from serum using C18-liquid chromatographic cartridges. After elution, samples were hydrolyzed with cholylglycine hydrolase, and methylated with dimethoxypropane, methanol, and concentrated $\mathrm{HCl}$. Bile acid methyl esters were further purified using a C8-liquid chromatographic cartridges, and derivatized to their trimethylsilyl ethers. The isotope ratios of chenodeoxycholate (CDCA) and cholate (CA) were determined by selected ion monitoring. The molar ratio of labeled to unlabeled bile acid in each sample $\left(\mathrm{MR}_{\mathrm{t}}\right)$ was determined from isotope ratios, and fractional turnover rate, pool size, and synthesis were calculated as described (43). Deoxycholate (DCA) pool was estimated from the same GC/MS runs by comparison of the intensity of its 370 ion to the intensity of the 370 ion of CDCA (42).

Statistical methods. Paired $t$ tests were used to compare the results of the measured variables off and on Premarin. For the analysis of the effects of Premarin in all 29 subjects, the results obtained in subjects studied twice, on both a low and high cholesterol diet, were averaged. $P$ values reflect the level of significance for a one-tailed test. The effects of Premarin and dietary cholesterol in the 13 subjects studied during both low and high intake of dietary cholesterol were evaluated using a $2 \times 2$ factorial design with multiple paired $t$ tests for three orthogonal contrasts: Premarin, dietary cholesterol, and interaction between Premarin and dietary cholesterol. One-tailed tests were used for the effects of Premarin and dietary cholesterol, but two-tailed tests were used for interactions. The variance about the mean was defined as the standard deviation in all results, tables, figures, and discussion, unless otherwise indicated. Single and multiple linear regression analysis was used to determine the significance of the relationships of the measured variables (44).

\section{Results}

In the sections that follow, all results are presented similarly, the effects of Premarin in all 29 subjects followed by the effects of dietary cholesterol in the subgroup of 13 . All measurements were not made in every subject.

Dietary intake of cholesterol. All subjects maintained adequate dietary records, and use of Premarin (Pr) did not alter cholesterol intake. The mean cholesterol $(\mathrm{CH})$ intake in milligrams per day ( $\pm 1 \mathrm{SD}$ ) for each study period is given: low $\mathrm{CH}$, off $\operatorname{Pr} 164 \pm 35$; low $\mathrm{CH}$, on $\operatorname{Pr} 175 \pm 56$; medium $\mathrm{CH}$, off $\operatorname{Pr}$ 496 \pm 80 ; medium $\mathrm{CH}$, on $\operatorname{Pr} 519 \pm 120$; high $\mathrm{CH}$, off $\operatorname{Pr}$ 755 \pm 107; high $\mathrm{CH}$, on Pr 805 \pm 95 .

Gallbladder motor function. The effects of Premarin on the volume and contraction of the gallbladder in response to an intravenous infusion of CCK8 was evaluated in 13 paired studies of 11 subjects. Premarin did not alter gallbladder motor function in response to CCK8 (off vs. on [ $n=13$ ]: FV, $23 \pm 8$ vs. $22 \pm 8 \mathrm{ml} ; \mathrm{RV}, 7 \pm 7$ vs. $7 \pm 8 \mathrm{ml} ; \% \mathrm{E}, 72 \pm 22$ vs. $74 \pm 20 \%$; $0.044 \pm 0.036$ vs. $0.045 \pm 0.042 \mathrm{~min}^{-1}$ ), or a regular meal (off vs. on [n = 6]: FV, $19 \pm 9$ vs. $17 \pm 4 \mathrm{ml} ; \mathrm{RV}, 6 \pm 6$ vs. $6 \pm 5 \mathrm{ml} ; \% \mathrm{E}$, $68 \pm 27$ vs. $67 \pm 20 \%$; $k, 0.031 \pm 0.031$ vs. $0.028 \pm 0.016 \mathrm{~min}^{-1}$ ).

Lipid composition of gallbladder bile (Fig. 1). Duodenal bile was obtained after stimulation of gallbladder contraction off and on Premarin in 11, 6, and 12 subjects, on a low, medium, and high cholesterol diet, respectively. Premarin increased the molar percent cholesterol (from $6.95 \pm 2.07$ to $7.98 \pm 2.95, P<0.04$ ) and the lithogenic index (from $1.11 \pm 0.28$ to $1.21 \pm 0.31, P<0.05)$ of bile. The relative percentage of CDCA decreased (from $38 \pm 6$ to $33 \pm 9, P<0.001$ ), and the percentage of DCA increased (from $22 \pm 10$ to $25 \pm 14, P$ $=0.05$ ). As a result, $[C A+D C A] / C D C A$ increased on Premarin (from $1.65 \pm 0.42$ to $2.10 \pm 0.88, P<0.002$ ).

The effect of dietary cholesterol on biliary lipid composi-
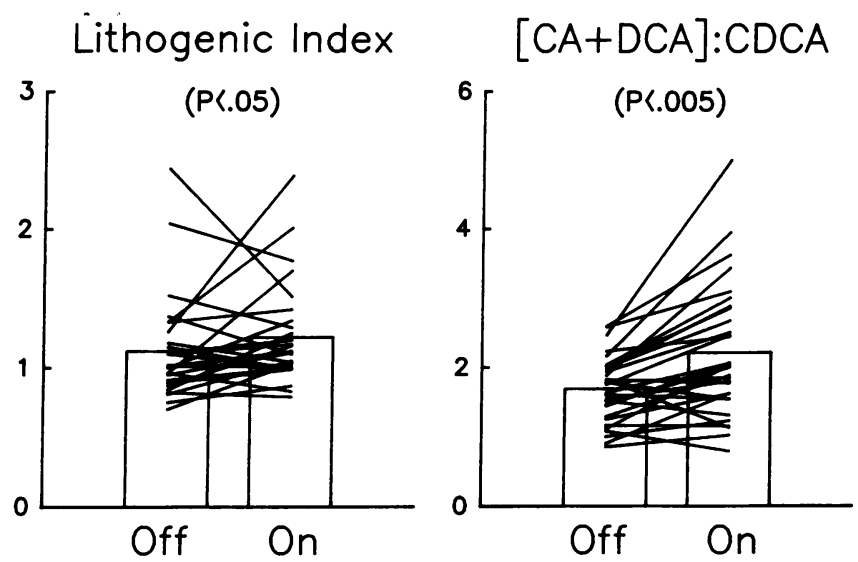

Figure 1. The composition of gallbladder bile is shown. Lithogenic index and [CA + DCA]/CDCA ratio increased during use of Premarin ("On").

tion was measured in 10 subjects (Table II). Unlike Premarin, increases in dietary cholesterol did not alter either the lithogenic index or the molar percent cholesterol of bile. The percent CA of bile increased and, as a result, the [CA + DCA]/ CDCA ratio increased with increasing dietary cholesterol (from $1.90 \pm 0.76$ to $2.12 \pm 0.80, P<0.05$ ).

Thus, only Premarin increased the relative amount of cholesterol in bile, but both Premarin and dietary cholesterol increased the $[C A+D C A] / C D C A$ ratio of gallbladder bile. The mechanisms of the increase in [CA + DCA]/CDCA ratio differed. Premarin lowered the percent CDCA and dietary cholesterol increased the percent CA. Increases in lithogenic index did not correlate with increases in [CA + DCA]/CDCA under any condition.

Biliary lipid secretion (Fig. 2). Secretion studies were completed off and on Premarin in 11, 5, and 9 subjects on a low, medium, and high cholesterol diet, respectively. Premarin increased biliary cholesterol secretion (from $1.51 \pm 0.47$ to $1.94 \pm 0.61 \mu \mathrm{mol} / \mathrm{kg}$ per h, $P<0.004$ ) without altering bile acid or phospholipid secretion. The secretion of cholesterol relative to the secretion of either bile acid (CH/BA) or phospholipid $(\mathrm{CH} / \mathrm{PL})$ increased on Premarin $(\mathrm{CH} / \mathrm{BA} .0477 \pm 0.0268$ vs. $0.0580 \pm 0.0275, P<0.01 ; \mathrm{CH} / \mathrm{PL} 0.2138 \pm 0.0576$ vs. $0.2466 \pm 0.0680, P<0.05)$.

Dietary cholesterol tended to increase biliary cholesterol secretion (from $1.70 \pm 0.77$ to $1.93 \pm 0.57 \mu \mathrm{mol} / \mathrm{kg}$ per h, $P$ $=0.07$ ) (Table II, Fig. 3), but the increase in cholesterol secretion was balanced by similar increases in bile acid (from $23.7 \pm 11.6$ to $29.0 \pm 7.8 \mu \mathrm{mol} / \mathrm{kg}$ per $\mathrm{h}, P<0.05$ ) and phospholipid secretion (from $5.8 \pm 2.0$ to $6.7 \pm 2.1 \mu \mathrm{mol} / \mathrm{kg}$ per $\mathrm{h}, P$ $=0.07)$. This accounts for the absence of a change in lithogenic index. In contrast, and consistent with the above findings, Premarin selectively increased biliary cholesterol secretion in this subgroup of nine subjects (from $1.65 \pm 0.75$ to $1.95 \pm 0.60 \mu \mathrm{mol} /$ kg per h, $P<0.005$ ).

Cholesterol metabolism (Fig. 4 and Table II). Cholesterol absorption was unaltered by Premarin (Fig. 4). However, in 11 subjects increases in dietary cholesterol were associated with a modest decrease in the percent of cholesterol absorbed (low vs. high cholesterol diet: $51 \pm 9$ vs. $45 \pm 8 \%$ off Premarin; $48 \pm 11$ vs. $44 \pm 7 \%$ on Premarin, $P<0.025)$. However, the mean increase in absolute amount of cholesterol absorbed between the low and high diet was $671 \mu \mathrm{mol} / \mathrm{d}$. 


\begin{tabular}{|c|c|c|c|c|c|c|c|}
\hline \multirow[b]{3}{*}{ Measured variable } & \multirow[b]{3}{*}{$n$} & \multicolumn{4}{|c|}{ Mean values* } & & \\
\hline & & \multicolumn{2}{|c|}{ Low $\mathrm{CH}$} & \multicolumn{2}{|c|}{ High CH } & \multicolumn{2}{|c|}{$P$ values ${ }^{t}$} \\
\hline & & Off & On & Off & On & Premarin & Diet \\
\hline \multicolumn{8}{|l|}{ Bile composition } \\
\hline GB LI & 10 & $1.14(0.11)$ & $1.32(0.14)$ & $1.03(0.08)$ & $1.13(0.11)$ & $\mathrm{I},<0.05$ & $\mathrm{D}, \mathbf{0 . 0 7}$ \\
\hline$[\mathrm{CA}+\mathrm{DCA}] / \mathrm{CDCA}$ & 12 & $1.66(0.17)$ & $2.13(0.26)$ & $1.79(0.13)$ & $2.44(0.33)$ & I, $<0.005$ & I, $<0.05$ \\
\hline \multicolumn{8}{|l|}{ Biliary lipid secretion $(\mu \mathrm{mol} / \mathrm{kg}$ per $h$ ) } \\
\hline Bile acid & 9 & $24.7(5.2)$ & $22.6(2.5)$ & $28.0(2.3)$ & $29.9(2.8)$ & NS & I, $<0.05$ \\
\hline Phospholipid & 9 & $5.4(0.7)$ & $6.1(0.6)$ & $6.4(0.6)$ & $6.9(0.8)$ & NS & I, 0.07 \\
\hline Cholesterol & 9 & $1.5(0.3)$ & $1.8(0.2)$ & $1.7(0.1)$ & $2.2(0.3)$ & I, $<0.005$ & I, 0.07 \\
\hline \multicolumn{8}{|l|}{ Cholesterol metabolism } \\
\hline Absorption (\%) & 11 & $51(3)$ & $48(3)$ & $45(3)$ & $44(2)$ & NS & $\mathrm{D},<0.025$ \\
\hline Synthesis (pmol/10 cell per $h$ ) & 11 & $60(5)$ & $63(5)$ & $61(5)$ & $57(3)$ & NS & NS \\
\hline Esterification $\left(\mathrm{pmol} / 10^{7}\right.$ cell per $\left.h\right)$ & 5 & $54(17)$ & $64(12)$ & $64(19)$ & $64(17)$ & NS & NS \\
\hline Remnant clearance $(\mathrm{ml} / \mathrm{min})$ & 7 & $43(4)$ & $55(9)$ & $47(4)$ & $52(6)$ & $\mathrm{I}, 0.06$ & NS \\
\hline \multicolumn{8}{|l|}{ Bile acid kinetics } \\
\hline \multicolumn{8}{|l|}{ Pools $(\mu \mathrm{mol} / \mathrm{kg})$} \\
\hline CDCA & 10 & $33(6)$ & $22(4)$ & $31(5)$ & $27(5)$ & $\mathrm{D},<0.025$ & NS \\
\hline $\mathrm{CA}$ & 9 & $48(11)$ & $30(5)$ & $45(7)$ & $33(8)$ & $\mathrm{D},<0.02$ & NS \\
\hline DCA & 10 & $21(4)$ & $24(5)$ & $21(5)$ & $29(6)$ & $\mathrm{I},<0.05$ & NS \\
\hline Total & 9 & $102(17)$ & $76(9)$ & $97(13)$ & $90(14)$ & NS & NS \\
\hline \multicolumn{8}{|l|}{ Synthesis $(\mu \mathrm{mol} / \mathrm{kg}$ per $d)$} \\
\hline CDCA & 10 & $5.1(1.2)$ & $3.5(0.5)$ & $4.7(0.6)$ & $4.6(1.2)$ & NS & NS \\
\hline $\mathrm{CA}$ & 9 & $7.7(1.6)$ & $6.1(1.0)$ & $8.5(1.4)$ & $5.9(0.7)$ & NS & NS \\
\hline Total & 9 & $12.8(2.7)$ & $9.2(1.2)$ & $13.2(2.0)$ & $9.9(1.6)$ & NS & NS \\
\hline \multicolumn{8}{|l|}{ FTR (d-1) } \\
\hline CDCA & 10 & $0.15(0.02)$ & $0.17(0.02)$ & $0.17(0.02)$ & $0.17(0.02)$ & NS & NS \\
\hline $\mathrm{CA}$ & 9 & $0.18(0.02)$ & $0.22(0.02)$ & $0.20(0.07)$ & $0.22(0.03)$ & I, $<0.02$ & NS \\
\hline
\end{tabular}

Abbreviations: $n$, number of subjects completing all four studies; CH, dietary cholesterol; GB LI, lithogenic index of gallbladder bile; FTR, fractional turnover rate; $I$, increased; $D$, decreased. ${ }^{*}$ Value in parentheses is the standard error of the mean. ${ }^{\ddagger} P$ values reflect the level of significance of the change in means due either to use of Premarin or to increasing dietary cholesterol. $P$ values were determined from multiple paired $t$ tests using a $2 \times 2$ factorial design.

Cholesterol synthesis by peripheral blood mononuclear cells was measured off and on Premarin in 12, 10, and 11 subjects on a low, medium, and high cholesterol diet, respectively, and was not altered by either Premarin or changes in dietary cholesterol.

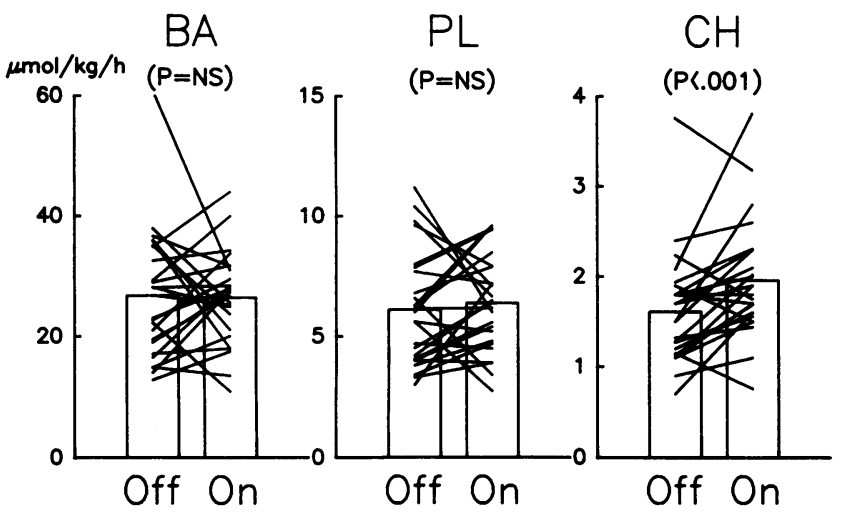

Figure 2. Biliary lipid secretion was measured by marker perfusion technique. The secretion of cholesterol (CH), but not bile acid (BA) or phospholipid (PL), increased during use of Premarin ("On").
Cholesterol esterification by peripheral blood mononuclear cells was measured off and on Premarin in six, nine, and five subjects on a low, medium, and high cholesterol diet, respectively. Cholesterol esterification increased on Premarin (from $90 \pm 63$ vs. $110 \pm 64.4 \mathrm{pmol} / 10^{7}$ cell per h, $P<0.03$ ). The effect of dietary cholesterol on cholesterol esterification could not be adequately evaluated because esterification was measured in only five subjects under conditions of both low and high dietary cholesterol.

The plasma clearance of chylomicron remnants was measured off and on Premarin in seven subjects during ingestion of both a low and high cholesterol diet. In 19 paired studies of 12 subjects, the clearance of remnants increased in 11 , was unchanged in 6, and decreased in 2 during use of Premarin. Premarin tended to increase remnant clearance (from $43 \pm 11$ to $55 \pm 19 \mathrm{ml} / \mathrm{min}, P=0.07$ ), but clearance was unaffected by dietary cholesterol.

Bile acid kinetics. Premarin and dietary cholesterol had divergent effects on the steady-state kinetics of bile acids. Kinetic measurements were made in 11,16 , and 11 subjects both off and on Premarin during ingestion of low, medium, or high cholesterol diets, respectively. Premarin preferentially decreased the pool of CDCA (from $29 \pm 13$ to $23 \pm 9 \mu \mathrm{mol} / \mathrm{kg}, P$ $<0.005$ ) without altering CA, DCA, or total pool. Premarin 

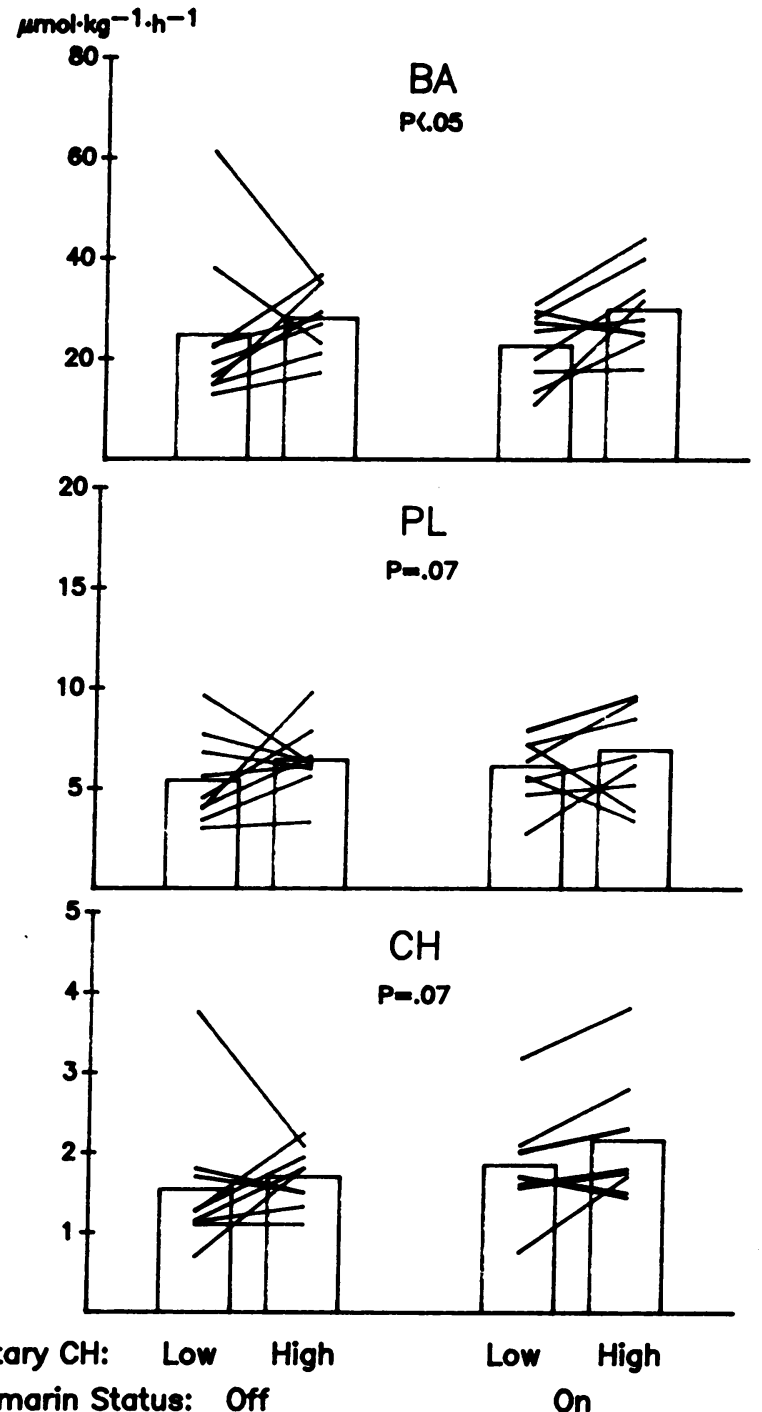

Premarin Status: Off

On

Figure 3. Biliary lipid secretion was measured off and on Premarin during ingestion of both a low and high cholesterol diet in nine subjects. Increased dietary cholesterol tended to increase the secretion of all three biliary lipids.

also inhibited CDCA synthesis (from $4.4 \pm 2.1$ to $3.7 \pm 1.7, P$ $<0.05$ ) (Fig. 5). The fractional turnover rates of both CDCA and CA were unchanged. The effects of dietary cholesterol on bile acid kinetics were determined in nine subjects (Table II).
Although increased dietary cholesterol did not independently stimulate the synthesis of total bile acid, CDCA, or CA, it did reverse the inhibitory effect of Premarin on CDCA pool and synthesis (Fig. 6).

Assessment of sterol balance by comparison of studies $o b$ tained during ingestion of low and high cholesterol diets (Table III). Overall sterol balance was assessed from the difference in total absorbed cholesterol, bile acid synthesis, and cholesterol secretion between low and high cholesterol diets. Since only a few subjects completed all of these studies off and on Premarin on both low and high cholesterol diets, group means were compared. Increments of 652 and $690 \mu \mathrm{mol} / \mathrm{d}$ of cholesterol were absorbed between the low and high cholesterol diets, off and on Premarin, respectively. Off Premarin, the increase in dietary cholesterol produced a $162 \mu \mathrm{mol} / \mathrm{d}$ increase in cholesterol excretion and no increase in bile acid synthesis, accounting for only $24 \%$ of the increase in dietary cholesterol. In contrast, on Premarin, the increase in dietary cholesterol produced a 382 $\mu \mathrm{mol} / \mathrm{d}$ increase in cholesterol excretion and a $86 \mu \mathrm{mol} / \mathrm{d}$ increase in bile acid synthesis, accounting for $68 \%$ of the increase in dietary cholesterol.

Relationship of biliary secretion of cholesterol to inputs to the hepatic free cholesterol pool: correlations off and on Premarin. We measured the following potential inputs to the hepatic pool of cholesterol: absolute cholesterol absorption from the intestine, cholesterol synthesis in peripheral blood monocytes as an estimate of hepatic cholesterol synthesis, and retinyl palmitate clearance as an estimate of chylomicron remnant clearance. Off Premarin, cholesterol synthesis in peripheral blood monocytes correlated with biliary cholesterol secretion during ingestion of the low cholesterol diet $(n=11, r=0.789, P$ $<0.004)$. Neither cholesterol absorption nor clearance of chylomicron remnants correlated with secretion. On Premarin, the clearance of chylomicron remnants correlated with biliary cholesterol secretion during ingestion of a low cholesterol diet ( $n=10, r=0.541, P=0.08$ ). Thus, during a low intake of cholesterol in postmenopausal women Premarin shifts the dependence of biliary cholesterol secretion away from newly synthesized cholesterol toward the uptake of lipoprotein cholesterol. Increased dietary cholesterol to the extent studied here eliminates any association of measured inputs to the hepatic cholesterol pool with the biliary secretion of cholesterol.

\section{Discussion}

Mechanisms of induction of cholesterol gallstones are incompletely understood. Women are at greater risk of developing

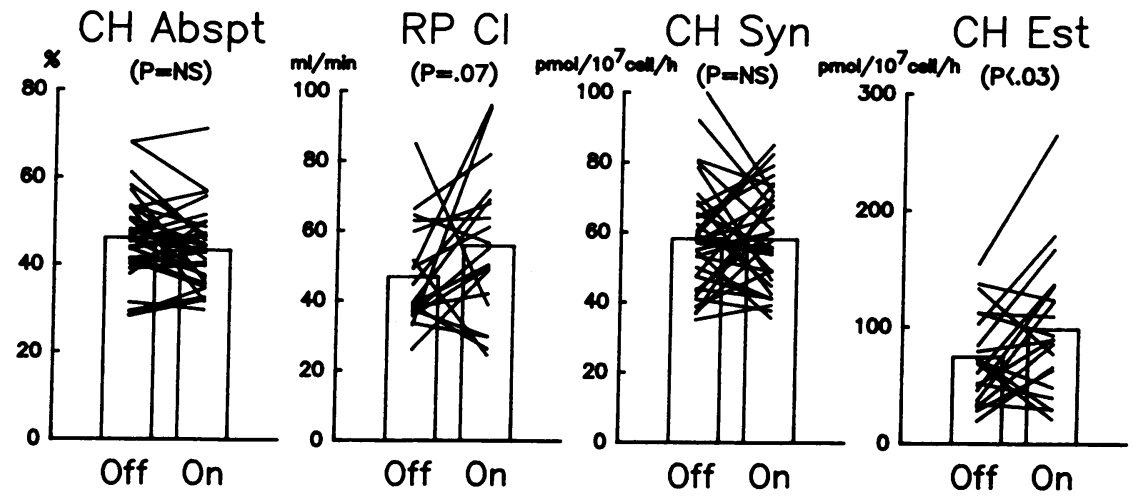

Figure 4. Cholesterol absorption from the intestine (CH Abspt) and cholesterol synthesis by peripheral blood monocytes (CH Syn) were not altered by use of Premarin. The clearance of retinyl palmitate $(\mathrm{RP} C \mathrm{Cl}$ ) and esterification of cholesterol by peripheral blood mononuclear cells $(\mathrm{CH}$ Est) increased during use of Premarin. 


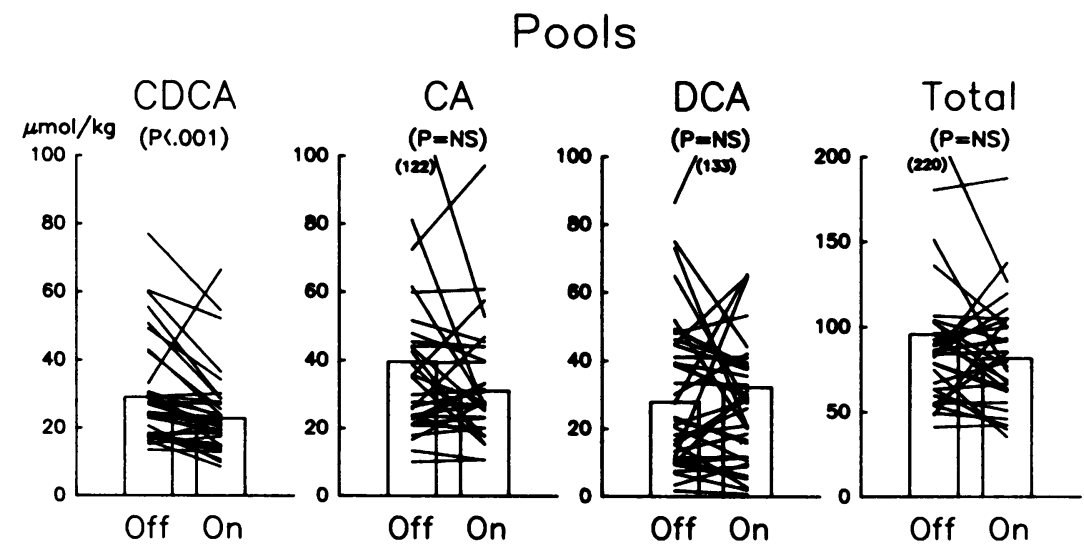

Synthetic Rates
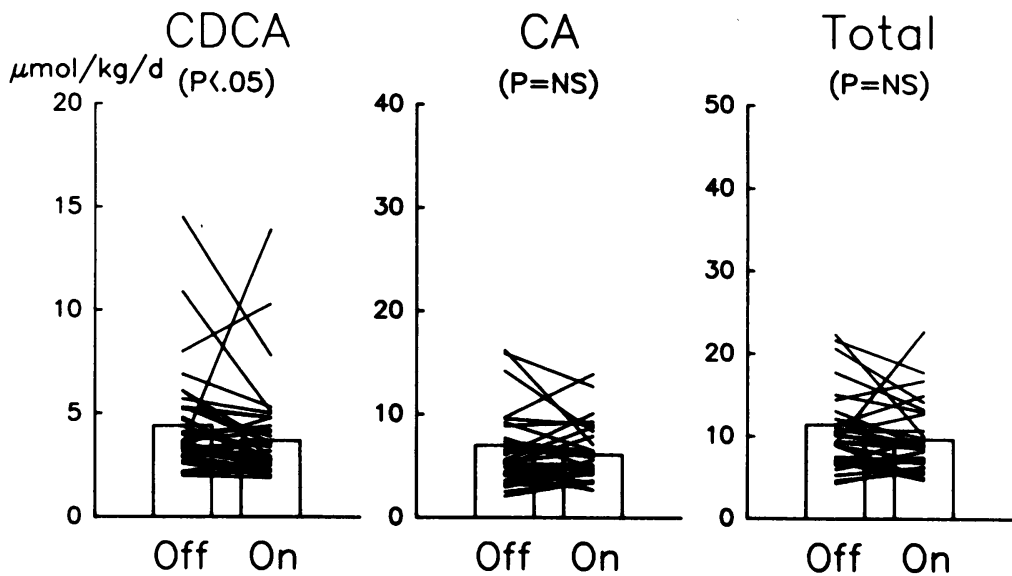

Figure 5. Bile acid kinetics. Premarin selectively decreased the pool size and synthesis of CDCA. CA pool and synthesis and DCA pool were not altered. cholesterol gallstones, and the risk is further increased by pregnancy $(1-5)$ and use of either contraceptive steroids $(6,7)$ or conjugated estrogens $(8,9)$. Use of Premarin, the most commonly prescribed preparation of conjugated estrogens for postmenopausal women, is associated with twice the risk of developing cholesterol gallstones (8). For these reasons, we studied the effects of Premarin on human hepatobiliary function.

There are several unique features of the present study that deserve special emphasis. We used a paired design to overcome the obstacle of the considerable interindividual variation in the various measurements of hepatic lipid metabolism. The number of subjects studied $(n=29)$ is far greater than that of any other study of the effects of estrogen, administered alone, on hepatic lipid metabolism. A relatively uniform dose of estrogen was used $(1.25 \mathrm{mg} / \mathrm{d}$ of Premarin). Most of the processes that regulate cholesterol metabolism were studied in healthy, freeliving subjects. Finally, by studying the effects of Premarin under varying levels of intake of dietary cholesterol, additional insight was gained into the mechanisms of the increase in biliary cholesterol induced by Premarin.

A prerequisite for the formation of cholesterol gallstones is the hepatic secretion of bile that is enriched in cholesterol. In the current study, we found that Premarin significantly increased the biliary secretion of cholesterol and the lithogenicity of gallbladder bile. Pertsemlidis et al. (20) demonstrated an increase in biliary cholesterol in two women taking a combination of conjugated estrogens plus medroxyprogesterone. In subsequent studies, contraceptive steroids $(13,16,17,45)$ and ethinyl estradiol $(18,19)$ increased biliary cholesterol. In one study, ethinyl estradiol (46) did not alter biliary cholesterol secretion. The majority of studies support the conclusion that estrogens, given alone or in combination with progestin, stimulate hepatic cholesterol secretion and increase the lithogenicity of bile.

The $18 \%$ increase in biliary cholesterol secretion induced by $1.25 \mathrm{mg} / \mathrm{d}$ Premarin was modest but similar to the $19 \%$ increase caused by low estrogen (30-35 $\mu \mathrm{g}$ of ethinyl estradiol) oral contraceptives (16). In contrast, biliary cholesterol increased $50 \%$ during intake of contraceptive steroids containing $50 \mu \mathrm{g}$ of ethinyl estradiol $(13,17)$. It seems likely that the increase in biliary cholesterol secretion is related to the dose and potency of estrogen used.

Biliary cholesterol originates from a metabolically active hepatic pool of free cholesterol. Inputs to this cholesterol pool include: de novo synthesis, hydrolysis of cholesterol ester, and lipoproteins removed from plasma via hepatic receptors. Irreversible outputs from the pool include biliary secretion of cholesterol, catabolism to bile acid, and secretion of very low density lipoprotein (VLDL) into plasma. In addition, cholesterol is reversibly removed from the pool by esterification to cholesterol ester. Biliary cholesterol secretion may increase if input to the hepatic pool of cholesterol is increased or if routes of output are inhibited.

Although estrogens stimulate the hepatic uptake of low 


\section{CDCA Pool}
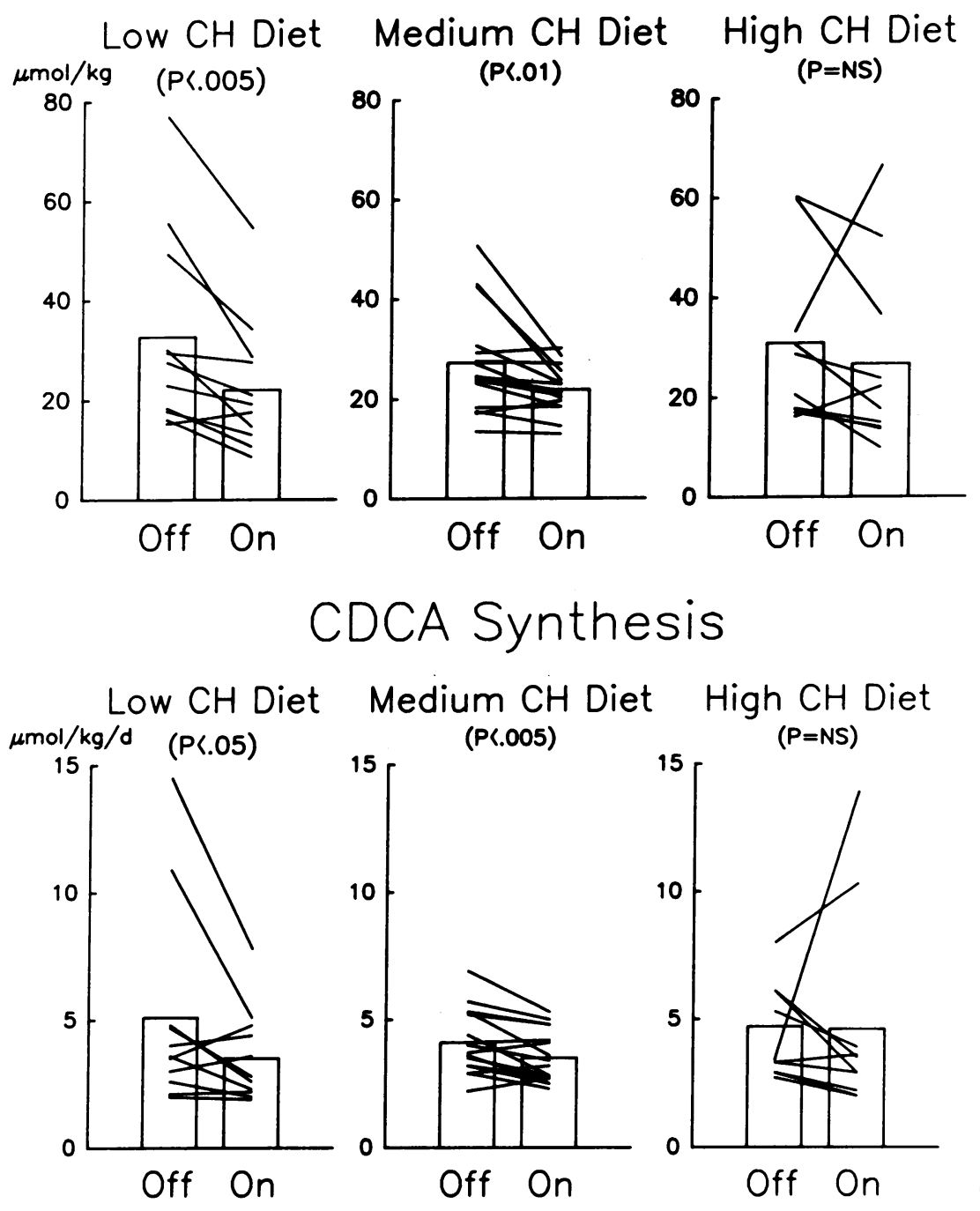

Figure 6. Increases in dietary cholesterol reversed the inhibitory effects of Premarin on CDCA pool size and synthesis. The reduction in CDCA pool and synthesis by Premarin on low and medium cholesterol diets was abolished by ingestion of a diet high in cholesterol ("High CH Diet").

density lipoproteins (LDL) (43), their effect on the hepatic uptake of chylomicron remnants is less clear. Remnant clearance is stimulated by estrogen treatment of rabbits or hypertriglyceridemic subjects and use of contraceptive steroids in women (47-49). Because chylomicron remnants can be removed by the LDL receptor $(43,50)$, their clearance may reflect the activity of not only a "remnant" receptor but also the LDL receptor. In a recent study (51), the hepatic LDL receptor was not required for binding of remnants to hepatic membranes, but was essential for internalization of the remnant. In our previous studies, contraceptive steroids containing $50 \mu \mathrm{g}$ of ethinyl estradiol increased the clearance of chylomicron remnants (48), but contraceptive steroids containing $35 \mu \mathrm{g}$ of ethinyl estradiol did not (16). In the present study, the clearance of chylomicron remnants tended to increase on Premarin. These data suggest that hepatic lipoprotein receptors may be stimulated by estrogenic activity equivalent to $50 \mu \mathrm{g}$ of ethinyl estradiol but only slightly by less estrogen. Alternatively, modest stimulation of lipoprotein receptors (especially the LDL receptor) by lower doses of estrogen may not be detected by the retinyl palmitate method.
Female steroid hormones have been shown to both inhibit (52) and stimulate (53) the activity of the rate-limiting enzyme in cholesterol biosynthesis, 3-hydroxy-3-methylglutaryl-coenzyme A (HMG-CoA) reductase. We found that preparations of contraceptive steroids, containing $35 \mu \mathrm{g}$ of ethinyl estradiol did not alter cholesterol synthesis by peripheral blood mononuclear cells (16). In the current study, Premarin did not alter cholesterol synthesis by these cells. Since there have been no studies comparing the effects of estrogen on cholesterol synthesis by hepatocytes and mononuclear cells, it could be argued that Premarin did alter hepatic cholesterol synthesis but did not influence cholesterol synthesis by the peripheral blood mononuclear cell. However, coordinate regulation of cholesterol synthesis by the liver and peripheral blood mononuclear cells has been shown in type II hyperlipoproteinemia and during cholesterol feeding, starvation, treatment with LDL cholesterol, and treatment with cholestyramine $(34,54,55)$. The failure of Premarin to alter cholesterol synthesis by mononuclear leukocytes may reflect a true lack of effect of estrogen on cholesterol synthesis, the low potency of Premarin, or less likely, differences in the response of various cell types. 
Table III. Sterol Balance off and on Premarin during Ingestion of Low and High Cholesterol Diets

\begin{tabular}{|c|c|c|c|c|c|c|c|}
\hline & & \multicolumn{6}{|c|}{ Study period } \\
\hline & & \multicolumn{3}{|c|}{ Off Premarin } & \multicolumn{3}{|c|}{ On Premarin } \\
\hline & & Low & High & Increment ${ }^{*}$ & Low & High & Increment \\
\hline & & \multicolumn{6}{|c|}{$\mu \mathrm{mol} / \mathrm{d}$} \\
\hline \multicolumn{8}{|l|}{ Input } \\
\hline Cholesterol $^{\ddagger}$ & $n$ & 12 & 12 & & 13 & 13 & \\
\hline \multirow[t]{2}{*}{ Absorption } & $\overline{\mathbf{X}}$ & 216 & 868 & 652 & 199 & 889 & 690 \\
\hline & SE & 23 & 57 & & 11 & 48 & \\
\hline \multicolumn{8}{|l|}{ Output } \\
\hline Cholesterol ${ }^{\S}$ & $n$ & 10 & 10 & & 12 & 10 & \\
\hline \multirow[t]{2}{*}{ Excretion } & $\overline{\mathbf{X}}$ & 1,437 & 1,599 & 162 & 1,770 & 2,161 & 382 \\
\hline & SE & 271 & 188 & & 221 & 261 & \\
\hline Bile acid & $n$ & 11 & 11 & & 11 & 10 & \\
\hline \multirow[t]{3}{*}{ Synthesis } & $\overline{\mathbf{X}}$ & 1,025 & 1,017 & -8 & 647 & 733 & 86 \\
\hline & $\mathrm{SE}$ & 298 & 186 & & 90 & 142 & \\
\hline & & & & \multicolumn{4}{|c|}{$\%$} \\
\hline (Input & $\frac{\text { Out }}{\text { put }}$ & $\stackrel{\text { tput }}{ } \times$ & $00 \%$ & & 24 & & 68 \\
\hline
\end{tabular}

* Increment refers to the increase in the mean of the measured variable when subjects went from a low to high intake of dietary cholesterol.

${ }^{\ddagger}$ Cholesterol absorption was calculated by multiplying total daily intake of cholesterol by the percent absorption.

${ }^{8}$ Estimated net excretion of cholesterol was the product of the 24-h biliary secretion rate of cholesterol and [ 1 - cholesterol absorption (\%)].

The lack of inhibition of cholesterol synthesis during use of Premarin may be viewed as inappropriate. As noted above, our data and other studies suggest that estrogen stimulates hepatic lipoprotein uptake. Under physiologic conditions, as the uptake of LDL or chylomicron remnants increases, the activity of HMG-CoA reductase decreases, reducing cholesterol synthesis (50). The inhibition of HMG-CoA reductase by lipoprotein cholesterol may be mediated by generation of regulatory oxysterols (56). Perhaps estrogen impairs the production of oxysterols, interfering with the feedback inhibition of HMGCoA reductase by lipoprotein cholesterol. Under this circumstance, estrogen would induce a net increase in hepatic cholesterol. The hepatocyte must then adapt by converting cholesterol to bile acid and cholesterol ester, or by excreting cholesterol into bile as free cholesterol.

Premarin inhibited the synthesis of CDCA and reduced the pool of CDCA. The relatively selective effect of Premarin on CDCA resulted in a decrease in the proportion of CDCA in bile and an increase in [CA + DCA]/CDCA ratio. In previous studies, we and others have demonstrated that oral contraceptives, containing both estrogen and progestin, inhibited CDCA and stimulated CA synthesis and pool $(13,17,21,45)$. Ethinyl estradiol, administered alone, decreased the percent CDCA in bile (46). Taken together, these data suggest that estrogens selectively inhibit the hepatic synthesis of CDCA.

Although increased dietary cholesterol did not independently stimulate bile acid synthesis, it reversed the inhibition of
CDCA synthesis induced by Premarin. Since Premarin enhances the hepatic clearance of chylomicron remnants, more cholesterol would be delivered to the liver for a given amount of dietary cholesterol. This may explain why bile acid synthesis was stimulated by increased dietary cholesterol only during use of Premarin. Other models of hepatic lipid metabolism have also suggested that the availability of cholesterol as substrate may regulate bile acid synthesis. Davis has shown that bile acid synthesis in isolated rat hepatocytes is directly correlated to levels of microsomal cholesterol (57). In addition, recent studies of human HepG2 cells suggest that increased uptake of LDL cholesterol stimulates bile acid synthesis (58). Taken together, these findings suggest that bile acid synthesis is stimulated by the availability of cholesterol substrate from lipoproteins.

Premarin altered the bile acid composition of bile and increased [CA + DCA]/CDCA. Three studies in humans have suggested that increases in this ratio induced by acute or chronic administration of bile acids are associated with an increase in lithogenic index of bile (59-61). In two of these studies, the increase in biliary cholesterol was related to either a decrease in CDCA or increase in CA $(59,60)$. In the third, the change in secretion was mainly due to an increase in DCA (61). In the present study, the increase in [CA + DCA]/CDCA induced by Premarin was due to a reduction in CDCA. Premarin also increased the lithogenicity of bile. However, increases in [CA + DCA]/CDCA did not correlate significantly with increases in lithogenic index under any condition of our study. Thus, the increase in [CA + DCA]/CDCA alone is insufficient to account for the relative increase in biliary cholesterol induced by Premarin.

Premarin stimulated cholesterol esterification by peripheral blood mononuclear cells. This effect could be due to either direct stimulation of acyl CoA-cholesterol-acyltransferase (ACAT) activity or enhancement of the substrate pool of cholesterol. Although enhancement of ACAT activity by pharmacologic doses of estrogen has been reported (62), we speculate that Premarin stimulated cholesterol esterification primarily via expansion of the free cholesterol pool by stimulation of hepatic lipoprotein uptake.

The hepatic pools of cholesterol destined for biliary secretion have not been completely defined, but it is clear that both lipoprotein cholesterol and newly synthesized cholesterol may be secreted into bile (63). In an earlier study (16), we found coordinate regulation of cholesterol metabolism during use of contraceptive steroid mixtures of estrogen and progestin. Specifically, as the rate of either cholesterol synthesis or chylomicron remnant uptake increased, there was a significant increase in biliary cholesterol secretion. However, as the contribution of cholesterol synthesis to biliary cholesterol secretion increased, the contribution from chylomicron remnants decreased. We postulated that these effects were due to suppression of ACAT activity by the progestin component of the contraceptive steroid mixture (64-66). With ACAT activity inhibited, any cholesterol entering the hepatocyte must leave as either biliary cholesterol, secreted VLDL, or newly synthesized bile acid. In the present study of Premarin, we observed an additive effect of cholesterol synthesis and remnant clearance on biliary cholesterol secretion. This is consistent with the unchanged or increased activity of ACAT during Premarin administration suggesting that cholesterol entering the hepatocyte may be esterified at a rate dependent upon substrate availability. Thus, only when input to the cholesterol pool is increased by stimulation 
of both cholesterol synthesis and remnant uptake, is there a direct correlation between input and the rate of secretion of biliary cholesterol.

An hypothesis for the effects of estrogen on hepatic lipid metabolism is suggested. Premarin increases biliary cholesterol by three mechanisms. First, Premarin stimulates hepatic lipoprotein receptors, increasing the input of cholesterol to the hepatic free cholesterol pool. Secondly, Premarin inhibits the formation of regulatory oxysterols so that the increased uptake of lipoprotein cholesterol is not associated with reduction of cholesterol synthesis. Thirdly, Premarin inhibits the catabolism of cholesterol to bile acid diminishing a major disposal path for hepatic free cholesterol. As a result, two remaining pathways of disposition of hepatic free cholesterol, biliary secretion of cholesterol and cholesterol esterification, are enhanced to accommodate the increased cholesterol load. Both cholesterol secretion and cholesterol esterification were increased significantly by Premarin. The cholesterol balance data of subjects ingesting various amounts of dietary cholesterol also support this hypothesis. Off Premarin, only $24 \%$ of the increment in absorbed dietary cholesterol between low and high cholesterol diets was excreted as cholesterol and newly synthesized bile acid. On Premarin, $68 \%$ of the increment in absorbed dietary cholesterol was excreted as these biliary sterols. In summary, a major effect of Premarin on total body cholesterol balance is to divert dietary cholesterol into bile and to increase the risk of cholesterol gallstones. This effect might also be regarded as a protective mechanism to decrease cholesterol accumulation in peripheral tissues, such as arterial macrophages.

\section{Acknowledgments}

The authors thank Radene Showalter, Laurance Morse, and Elaine Butler for excellent technical assistance; Mary Lu Jones for help with dietary control; and Teresa Boulay for preparation of the manuscript. We also acknowledge the assistance of Drs. Craig Fausel, Frieder Berr, and Michael Lawson, who participated in the conduct of some of these studies. We especially appreciate the help of Drs. Phil Archer and Gary Zerbe, Department of Preventive Medicine and Biometrics, University of Colorado School of Medicine, who provided valuable consultation in the statistical analysis of the data.

This work was supported by the following National Institutes of Health grants: 5 R01 DK-19605 and 2 R01 DK-31765. Additional support for these studies was provided by the Hepatobiliary Center of the University of Colorado Health Science Center (U. S. Public Health Service grant DK-34914) and the General Clinical Research Center Program of the Division of Research Resources, National Institutes of Health (grant RR-00051).

\section{References}

1. Friedman, G. A. D., W. B. Kannel, and T. R. Dawber. 1966. The epidemiology of gallbladder disease: observations in the Framingham study. J. Chron. Dis. 19:273-292.

2. Layde, P. M., M. P. Vessey, and D. Yeates. 1982. Risk factors for gallbladder disease: a cohort study of young women attending family planning clinics. $J$. Epidemiol. Community Med. 36:274-278.

3. Rome Group for the Epidemiology and Prevention of Cholelithiasis (GREPCO). 1984. Prevalence of gallstone disease in an italian adult female population. Am. J. Epidemiol. 119:796-805.

4. Barbara, L., C. Sama, A. M. M. Labate, F. Taroni, A. G. Rusticali, D. Festi, C. Sapio, E. Roda, C. Banterle, A. Puci, et al. 1987. A population study on the prevalence of gallstone disease: the Sirmione study. Hepatology (Baltimore). 7:913-917.

5. Scragg, R. K. R., A. J. McMichael, and R. F. Seamark. 1984. Oral contraceptives, pregnancy, and endogenous oestrogen in gall stone disease-A casecontrol study. Br. Med. J. 288:1795-1799.
6. Boston Collaborative Drug Surveillance Program. 1973. Oral contraceptives and venous thromboembolic disease, surgically confirmed gallbladder disease, and breast tumors. Lancet. 5:1399-1404.

7. Royal College of General Practitioners. 1974. Oral Contraceptives and Health. Pitman Medical, Manchester, England. 57-59.

8. Boston Collaborative Drug Surveillance Program. 1974. Surgically confirmed gallbladder disease, venous thromboembolism, and breast tumors in relation to post-menopausal estrogen therapy. N. Engl. J. Med. 290:15-19.

9. The Coronary Drug Project Research Group. 1977. Gallbladder disease as a side effect of drugs influencing lipid metabolism: experience in the Coronary Drug Project. N. Engl. J. Med. 296:1185-1190.

10. Braverman, D. Z., M. L. Johnson, and F. Kern, Jr. 1980. Effects of pregnancy and contraceptive steroids on gallbladder function. $N$. Engl. J. Med. 302:362-364.

11. Everson, G. T., C. McKinley, M. Lawson, M. Johnson, and F. Kern, Jr. 1982. Gallbladder function in the human female: Effect of the ovulatory cycle, pregnancy, and contraceptive steroids. Gastroenterology. 82:711-719.

12. Ylostalo, P., P. Kirkinen, J. Heikkinen, O. Maentausta, and P. A. Jarvinen. 1982. Gallbladder volume and serum bile acids in cholestasis of pregnancy. Br. J. Obstet. Gynaecol. 89:59-61.

13. Kern, F., Jr., G. T. Everson, B. DeMark, C. McKinely, R. Showalter, D. Z. Braverman, P. Szczepanik-VanLeeuwen, and P. D. Klein. 1982. Biliary lipids, bile acids, and gallbladder function in the human female: effects of contraceptive steroids. J. Lab. Clin. Med. 99:798-805.

14. Shaffer, E. A., P. J. Taylor, K. Logan, S. Gadomski, and B. Corenblum. 1984. The effect of a progestin on gallbladder function in young women. Am. J. Obstet. Gynecol. 148:504-507.

15. Kern, F., Jr., G. T. Everson, B. DeMark, C. McKinley, R. Showalter, W. Erfling, D. Z. Braverman, P. Szczepanik-VanLeeuwen, and P. D. Klein. 1981. Biliary lipids, bile acids, and gallbladder function in the human female: effects of pregnancy and the ovulatory cycle. J. Clin. Invest. 68:1229-1242.

16. Kern, F., Jr., and G. T. Everson. 1987. Contraceptive steroids increase cholesterol in bile: mechanisms of action. J. Lipid Res. 28:828-839.

17. Bennion, L. J., D. M. Mott, and B. V. Howard. 1980. Oral contraceptives raise the cholesterol saturation of bile by increasing biliary cholesterol secretion. Metab. Clin. Exp. 29:18-22.

18. Heuman, R., E. L. F. Larsson-Cohn, M. Hammer, and H. Tiselius. 1979. Effects of postmenopausal ethinyl estradiol treatment on gallbladder bile. Naturitas. 2:69-72.

19. Anderson, A., O. F. W. James, H. S. MacDonald, S. Snowball, and W. Taylor. 1980. The effect of ethynyl oestradiol on biliary lipid composition in young men. Eur. J. Clin. Invest. 10:77-80.

20. Pertsemlidis, P., P. Panveliwalla, and E. H. Ahrens, Jr. 1974. Effects of clofibrate and an estrogen-progestin combination on fasting biliary lipids and cholic acid kinetics in man. Gastroenterology. 66:565-573.

21. Everson, G. T., P. Fennessey, and F. Kern, Jr. 1988. Contraceptive steroids alter the steady-state kinetics of bile acids. J. Lipid Res. 29:68-76.

22. DenBesten, L., W. E. Connor, and S. Bell. 1973. The effect of dietary cholesterol on the composition of human bile. Surgery. 73:226-273.

23. Lee, D. W. T., C. J. Gilmore, G. Bonorris, H. Cohen, J. W. Marks, M. Cho-Sue, M. S. Meiselman, and L. J. Schoenfield. 1985. Effect of dietary cholesterol on biliary lipids in patients with gallstones and normal subjects. Am. J. Clin. Nutr. 42:414-420.

24. Dam, H., I. Kruse, M. K. Jensen, H. E. Kallehauge, and H. J. Fenger. 1971. Studies on human bile. IV. Influence of ingestion of cholesterol in the form of eggs on the composition of bile in healthy subjects. $Z$. Ernaehrungswiss. 10:178-187.

25. Andersen, E., and K. Hellstrom. 1979. The effect of cholesterol feeding on bile acid kinetics and biliary lipids in normolipidemic and hypertriglyceridemic subjects. J. Lipid Res. 20:1020-1027.

26. Quintao, E., S. M. Grundy, and E. H. Ahrens, Jr. 1971. Effects of dietary cholesterol on the regulation of total body cholesterol in man. J. Lipid Res. 12:232-247.

27. Nestel, P. H., and A. Poyser. 1976. Changes in cholesterol synthesis and excretion when cholesterol intake is increased. Metab. Clin. Exp. 25:1591-1599.

28. Grundy, S. M., and H. Y. I. Mok. 1979. Effect of diets and drugs on biliary cholesterol secretion in man. In Gallstones. M. M. Fisher, C. A. Goresky, E. A. Shaffer, and F. M. Strasbert, editors. Plenum Publishing Corp. New York. 238298.

29. White, E. C., D. J. McNamara, and E. H. Ahrens, Jr. 1981. Validation of a dietary record system for the estimation of the daily cholesterol intake in individual outpatients. Am. J. Clin. Nutr. 34:199-203.

30. Everson, G. T., D. Z. Braverman, M. L. Johnson, and F. Kern, Jr. 1980. A critical evaluation of real-time ultrasonography for the study of gallbladder volume and contraction. Gastroenterology. 79:40-46.

31. Davis, R. A., P. M. Hyde, J.-C. W. Kuan, M. Malone-McNeal, and J. Archambault-Schexnayder. 1983. Bile acid secretion by cultured rat hepatocytes. J. Biol. Chem. 258:3661-3667.

32. Bartlett, G. R. 1959. Phosphorus assay in column chromatography. $J$. Biol. Chem. 234:466-468. 
33. Thomas, P. J., and A. F. Hofmann. 1973. A simple calculation of the lithogenic index of bile: Expressing biliary lipid composition on rectangular coordinates. Gastroenterology. 65:698-700.

34. Grundy, S. M., and A. L. Metzger. 1972. A physiological method for estimation of hepatic secretion of biliary lipids in man. Gastroenterology 62:1200-1217.

35. Hazzard, W. R., and E. L. Bierman. 1976. Delayed clearance of chylomicron remnants following vitamin A-containing oral fat loads in broad- $\beta$ disease

(Type III hyperlipoproteinemia). Metab. Clin. Exp. 25:777-801.

36. Wilson, D. E., I.-F. Chan, and M. Ball. 1983. Plasma lipoprotein retinoids after vitamin A feeding in normal man: minimal appearance of retinyl esters among low density lipoproteins. Metab. Clin. Exp. 32:514-517.

37. Wilson, D. E., I.-F. Chan, K. N. Buchi, and S. C. Horton. 1985. Postchallenge plasma lipoprotein retinoids: chylomicron remnants in endogenous hypertriglyceridemia. Metab. Clin. Exp. 34:551-558.

38. Wilson, D. E., I.-F. Chan, A. K. Cheung, W. Dutz, and K. N. Buchi. 1985 Retinyl ester retention in chronic renal failure: further evidence for a defect in chylomicron remnant metabolism. Atherosclerosis. 57:187-189.

39. Berr, F., and F. Kern, Jr. 1984. Plasma clearance of chylomicrons labeled with retinyl palmitate in healthy human subjects. J. Lipid Res. 25:805-812.

40. Berr, F., R. Eckel, and F. Kern, Jr. 1985. Plasma decay of chylomicron remnants is not affected by heparin-stimulated plasma lipolytic activity in normal fasting man. J. Lipid Res. 26:852-859.

41. Cortner, J. A., P. M. Coates, N.-A. Le, D. R. Cryer, M. C. Ragni, A Faulkner, and T. Langer. 1987. Kinetics of chylomicron remnant clearance in normal and in hyperlipoproteinimic subjects. J. Lipid Res. 28:195-206.

42. Everson, G. T. 1987. Steady-state kinetics of serum bile acids in healthy human subjects: single and dual isotope techniques using stable isotopes and mass spectrometry. J. Lipid Res. 28:238-252.

43. Brown, M. S., and J. L. Goldstein. 1983. Lipoprotein receptors in the liver. J. Clin. Invest. 72:743-747.

44. Draper, N. R., and H. Smith. 1981. Applied Regression Analysis, 2nd edition. John Wiley \& Sons, Inc., New York. 458-487.

45. van der Werf, S. D. J., G. P. van Berge Henegouwen, A. T. Ruben, and D. M. H. Palsma. 1987. Biliary lipids, bile acid metabolism, gallbladder motor function and small intestinal transit during ingestion of a sub-fifty oral contraceptive. J. Hepatol. 4:318-326.

46. Down, R. H. L., M. J. Whiting, J. M. Watts, and W. Jones. 1983. Effect of synthetic oestrogens and pogestagens in oral contraceptives on bile lipid composition. Gut. 24:253-259.

47. Kushwaha, R. S., W. R. Hazzard, C. Gagne, A. Chait, and J. J. Albers 1977. Type III hyperlipoproteinemia: paradoxical hypolipidemic response to estrogen. Ann. Intern. Med. 87:517-523.

48. Berr, F., R. H. Eckel, and F. Kern, Jr. 1986. Contraceptive steroids increase hepatic uptake of chylomicron remnants in healthy young women. J. Lipid Res. 27:645-651.

49. Floren, C., R. S. Kushuaha, W. R. Hazzard, and J. J. Albers. 1981. Estrogen-induced increase in uptake of cholesterol-rich very low density lipoproteins in perfused rabbit liver. Metab. Clin. Exp. 30:367-375.

50. Havel, R. J., and R. L. Hamilton. 1988. Hepatocytic lipoprotein receptors and intracellular lipoprotein catabolism. Hepatology (Baltimore). 8:1689-1704.

51. Nagata, Y., J. Chen, and A. D. Cooper. 1988. Role of low density lipopro- tein receptor-dependent and -independent sites in binding and uptake of chylomicron remnants in rat liver. J. Biol. Chem. 263:15151-15158.

52. Leoni, S., S. Spagnulo, C. Virgiliis, M. T. Margiantini, and A. Trentulance. 1984. Cholesterol synthesis and related enzymes in rat liver during pregnancy. Experientia (Basel). 40:703-704.

53. Feingold, K. R., T. Wiley, A. H. Moser, S. R. Lear, and M. H. Wiley. 1984

De novo cholesterogenesis in pregnancy. J. Lab. Clin. Med. 101:256-263.

54. Harwood, H. J., M. Schneider, and P. W. Stacpoole. 1984. Measurement of human leukocyte microsomal HMG-CoA reductase activity. J. Lipid Res. 25:967-978.

55. Mistry, P., N. E. Miller, M. Laker, W. R. Hazzard, and B. Lewis. 1981. Individual variation in the effects of dietary cholesterol on plasma lipoproteins and cellular cholesterol homeostasis in man: Studies of low density lipoprotein receptor activity and 3-hydroxy-3-methylglutaryl coenzyme A reductase activity in blood mononuclear cells. J. Clin. Invest. 67:493-502.

56. Saucier, S. E., A. A. Kandutsch, F. R. Taylor, T. A. Spencer, S. Phirwa, and A. K. Gayen. 1985. Identification of regulatory oxysterols, 24(S),25-epoxycholesterol and 25-hydroxycholesterol, in cultured fibroblasts. J. Biol. Chem. 260:14571-14579.

57. Davis, R. A., T. S. Elliott, and G. R. Laffier. 1986. Regulation of bile acid synthesis via direct effects on the microsomal membrane. Biochemistry. 25:1632-1636.

58. Kempen, H. J., E. Lommerse, R. VanSchie, E. Hepp, P. Meyer, and H. Princen. 1988. Bile acid synthesis by human hepatoma cell line HepG2 is stimulated by low density lipoprotein. Biochem. Soc. Trans. 16:566-567.

59. Lindblad, L., K. Lundholm, and T. Schersten. 1977. Influence of cholic and chenodeoxycholic acid on biliary cholesterol secretion in man. Eur. J. Clin. Invest. 7:383-388.

60. Sama, C., N. F. LaRusso, V. Lopez del. Pino, and J. L. Thistle. 1982. Effects of acute bile acid administration on biliary lipid secretion in healthy volunteers. Gastroenterology. 82:515-525.

61. Carulli, N., P. Loria, M. Bertolotti, M. Ponz de Leon, D. Menozzi, G. Medici, and I. Piccagli. 1984. Effects of acute changes of bile acid pool composition of biliary lipid secretion. J. Clin. Invest. 74:614-624.

62. Davis, R. A., R. Showalter, and F. Kern, Jr. 1978. Reversal by triton WR-1339 of ethinyl estradiol-induced hepatic cholesterol esterification. Biochem. J. 174:45-51.

63. Robins, S. J., J. M. Fasulo, M. A. Collins, and G. M. Patton. 1985. Evidence for separate pathways of transport of newly synthesized and preformed cholesterol into bile. J. Biol. Chem. 260:6511-6513.

64. Nervi, F., M. Bronfman, W. Allalon, E. Depiereux, and R. Del Pozo 1984. Regulation of biliary cholesterol secretion in the rat. J. Clin. Invest. 74:2226-2237.

65. Nervi, F. O., R. Del Pozo, C. F. Covarrubian, and B. O. Ronco. 1983. The effect of progesterone on the regulatory mechanisms of biliary cholesterol secretion in the rat. Hepatology (Baltimore). 3:360-367.

66. Stone, B. G., S. K. Erickson, W. Y. Craig and A. D. Cooper. 1985 Regulation of rat biliary cholesterol secretion by agents that alter intrahepatic cholesterol metabolism. J. Clin. Invest. 76:1773-1781.

67. Johnson, R., R. Masserano, R. Haring, B. Kho, and G. Schilling. 1975 Quantitative GLC determination of conjugated estrogens in raw material and finished dosage forms. J. Pharm. Sci. 64:1007-1011. 